\title{
Community-based approaches to prevention of mother-to-child transmission of HIV: Findings from a low-income community in Kenya
}

\author{
Susan Kaai \\ Population Council \\ Carolyn Baek \\ Population Council \\ Scott Geibel \\ Population Council \\ Peter Omondi \\ Benson Ulo
}

See next page for additional authors

Follow this and additional works at: https://knowledgecommons.popcouncil.org/departments_sbsr-hiv

Part of the Demography, Population, and Ecology Commons, Health Policy Commons, Immune System Diseases Commons, International Public Health Commons, Maternal and Child Health Commons, Medicine and Health Commons, Public Health Education and Promotion Commons, Virus Diseases Commons, and the Women's Health Commons How does access to this work benefit you? Let us know!

\section{Recommended Citation}

Kaai, Susan, Carolyn Baek, Scott Geibel, Peter Omondi, Benson Ulo, Grace Muthumbi, Carol Nkatha, and Naomi Rutenberg. 2007. "Community-based approaches to prevention of mother-to-child transmission of HIV: Findings from a low-income community in Kenya," Horizons Final Report. Nairobi: Population Council. 


\section{Authors}

Susan Kaai, Carolyn Baek, Scott Geibel, Peter Omondi, Benson Ulo, Grace Muthumbi, Carol Nkatha, and Naomi Rutenberg 
Community-based Approaches to Prevention of Mother-to-Child Transmission of HIV: Findings from a Low-income Community in Kenya

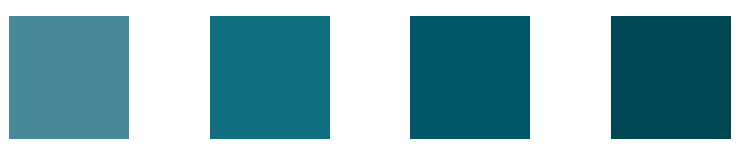

Horizons Program International Medical Corps Steadman Research Services International 


\section{Community-based Approaches to Prevention of Mother-to-Child Transmission of HI V: Findings from a Low-income Community in Kenya}

Susan Kaai ${ }^{1}$, Carolyn Baek ${ }^{1}$, Scott Geibel ${ }^{1}$, Peter Omondi ${ }^{2}$, Benson $\mathrm{Ulo}^{2}$, Grace Muthumbi ${ }^{2}$, Carol Nkatha ${ }^{3}$, and Naomi Rutenberg ${ }^{1}$

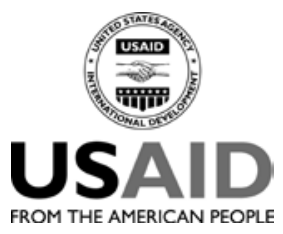

\section{Hgrizons}
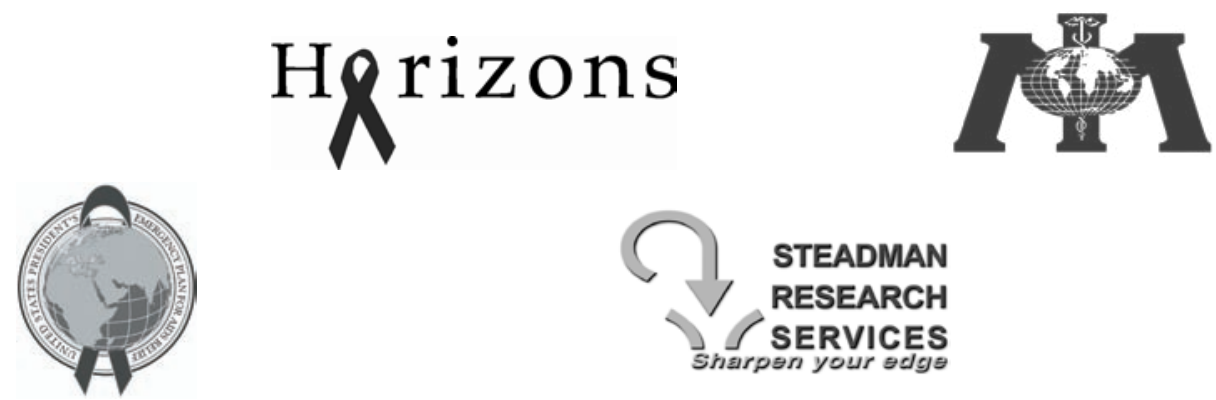

\footnotetext{
${ }^{1}$ Horizons/Population Council

${ }^{2}$ International Medical Corps

${ }^{3}$ Steadman Research Services International
} 


\section{Acknowledgments}

The authors would like to thank the study participants for their consent and time.

We would like to thank the research assistants who participated in the data collection exercise. We are grateful to the National Council for Science and Technology for approving the study and the Provincial Medical Officer of health for granting us permission to access selected public health facilities in the study area. Special thanks to Dr. Festus Ilako, head of programs at AMREF for allowing us use of the AMREF clinic. In addition we would like to thank the study site managers of the following health facilities: Woodley health center, Lang'ata health center, Kibera health center, Ngong road health center, Riruta health center, Wanga clinic, and AMREF clinics.

We would like to thank members of the study's technical advisory committee for their input in both the intervention implementation and reviewing the research questionnaires and in-depth interview study guides.

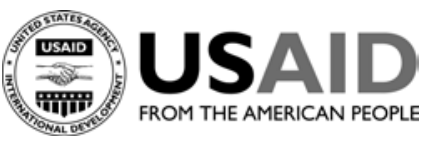

This study was supported by the Horizons Program, which is implemented by the Population Council in collaboration with the International Center for Research on Women, International HIV/AIDS Alliance, PATH, Tulane University, Family Health International, and Johns Hopkins University. Horizons is funded by the President's

Emergency Plan for AIDS Relief through the U.S. Agency for International Development, under the terms of HRN-A-00-9700012-00. The opinions expressed herein are those of the authors and do not necessarily reflect the views of the U.S. Agency for International Development.

Published in August 2007.

\section{(2) Population Council}

The Population Council is an international, non-profit, nongovernmental institution that seeks to improve the well-being and reproductive health of current and future generations around the world and to help achieve a humane, equitable, and sustainable balance between people and resources. The Council conducts biomedical, social science, and public health research and helps build research capacities in developing countries. Established in 1952, the Council is governed by an international board of trustees. Its New York headquarters supports a global network of regional and country offices.

Copyright @ 2007. The Population Council Inc.

Suggested citation: Kaai, Susan, Carolyn Baek, Scott Geibel, Peter Omondi, Benson Ulo, Grace Muthumbi, Carol Nkatha, and Naomi Rutenberg. 2007. "Community-based approaches to prevention of mother-to-child transmission of HIV: Findings from a low-income community in Kenya,” Horizons Final Report. Washington, DC: Population Council.

This document may be reproduced in whole or in part without permission of the Population Council provided full source citation is given and the reproduction is not for commercial purposes. 


\section{Table of Contents}

\section{Acronyms and Abbreviations}

Executive Summary 1

Why test community approaches to PMTCT? 2

$\begin{array}{ll}\text { Methods } & 4\end{array}$

Study objective $\quad 4$

Description of the intervention $\quad 4$

Study partners $\quad 4$

Study sites $\quad 4$

Study design $\quad 5$

Implementation of the interventions 5

$\begin{array}{ll}\text { Data collection procedures } & 7\end{array}$

Ethical procedures $\quad 8$

Data management and analysis $\quad 9$

Limitations $\quad 9$

$\begin{array}{ll}\text { Results } & 10\end{array}$

$\begin{array}{ll}\text { Profile of the respondents } & 10\end{array}$

Summary of study findings $\quad 11$

Trends of key study outcomes by study arms 12

Challenges to the implementation of the community-based intervention 24

Conclusions $\quad 26$

$\begin{array}{lr}\text { References } & 28\end{array}$ 


\section{Acronyms and Abbreviations}

AIDS

ART

ARV

ANC

AMREF

HIV

IMC

$\mathrm{MCH}$

MTCT

NASCOP

PMTCT

SRSI

STI

TBA

UN

UNICEF

USAID

VCT
Acquired immune deficiency syndrome

Antiretroviral therapy

Antiretroviral

Antenatal care

African Medical and Research Foundation

Human immunodeficiency virus

International Medical Corps

Maternal and child health

Mother-to-child transmission

National AIDS and STI Control Program

Prevention of mother-to-child transmission

Steadman Research Services International

Sexually transmitted infection

Traditional birth attendant

United Nations

United Nations Children’s Fund

Unites States Agency for International Development

Voluntary counseling and testing 


\section{Executive Summary}

The Horizons Program, in partnership with International Medical Corps (IMC) and Steadman Research Services International (SRSI), conducted an intervention study in Kibera, an urban slum in Nairobi, to determine what effect three different community-based activities had on utilization of key prevention of mother-to-child transmission (PMTCT) services. The interventions included moving services closer to the population via mobile clinics, as well as increasing psychosocial support through the use of traditional birth attendants (TBAs) and peer counselors as PMTCT promoters.

Researchers used a pre-/post-test evaluation 4-cell design (three experimental intervention arms and a comparison arm with no additional community activities) to assess the outcomes of the pilot project. Each arm corresponded to a distinct sub-area of the Kibera slum. At baseline (June 2004), a total of 1,803 women took part in exit interviews at the clinics. In October and November 2004, researchers conducted in-depth interviews to further explore issues raised in the quantitative survey. The convenience sample included 24 HIV-positive women and five HIV-negative women with infants aged 10 weeks or younger. These women were selected from the four study arms. Interviews were conducted in Kiswahili, recorded, transcribed, and then translated into English.

Baseline data collection was followed by the implementation of the community intervention (use of mobile clinic, TBAs, and HIV-positive peer counselors) for about 12 months. A second crosssectional follow-up survey was conducted at the clinics among 1,813 women between August and October 2005 to assess the effect of the intervention on the study outcomes. Twenty-nine in-depth interviews (with 24 HIV-positive and five HIV-negative women) were also conducted.

Data from the study showed that there were positive trends during the study period in most of the PMTCT indicators, including knowledge of MTCT, antenatal care (ANC) utilization, and delivery in health facilities. However, it is not possible to attribute all these positive trends to the communitybased interventions because similar positive trends were observed at the comparison site, with the exception of infant feeding indicators, TBA utilization during last pregnancy, and Nevirapine uptake. The inability to measure a greater effect of the interventions may be due to the small proportion of the study respondents (16 percent) who reported interaction with the mobile clinic providers, TBAs, or HIV-positive peer counselors. 


\section{Hgrizons}

\section{Why Test Community Approaches to PMTCT?}

Clinical trials set in Thailand in 1998 and in Uganda in 1999 demonstrated that the risk of vertical transmission of HIV from a pregnant woman to her infant can be reduced by nearly 50 percent by administering short-course or single dose antiretroviral prophylaxis in the last weeks of pregnancy or at the onset of labor together with an infant dose (Shaffer et al. 1999). Based on these results, UNICEF supported the initiation of pilot prevention of mother-to-child transmission (PMTCT) programs in 11 countries, nine of which were in sub-saharan Africa. The full package of PMTCT services included opt-out HIV counseling and testing (CT), improved obstetric practices, antiretroviral therapy (ART), counseling and support for safer infant feeding practices, and family planning ${ }^{1}$. Evaluations of the UN-supported programs found that it is feasible to integrate PMTCT services into the antenatal (ANC) and maternal and child health (MCH) setting in low resource countries.

In 2005, it was estimated that only 9 percent of pregnant women with HIV in low- and middle-income countries were receiving antiretroviral (ARV) prophylaxis for preventing mother-to-child transmission of HIV, an increase from 3 percent in 2003 (UNAIDS 2006). This modest progress can be attributed partly to a decentralized approach in offering PMTCT services, political commitment, and support from the US President's Emergency Plan for AIDS Relief (UNICEF 2007). However, coverage is still far from optimal. In part this is due to supply side issues such as overburdened staff. But there is also lack of demand for women to accept all the services that make up PMTCT programs (Rutenberg et al. 2003).

The medical recommendations of PMTCT programs are often difficult for women to implement as they are overshadowed by community norms, values, and beliefs. A woman's decision to participate fully in a PMTCT program is influenced by the opinions of her partner and other family and community members, as well as by her perceptions and fears of possible negative reactions by others. Partners, parents, in-laws, and other relatives have varying degrees of influence on testing, disclosure, and drug treatment, and often have significant authority over infant feeding. In many instances, if women do decide on their own to adhere to all of the recommended practices, they are going against social norms. An example is the issue of infant feeding, for which neither one of the recommended behaviors for HIV positive women-breastmilk substitutes or exclusive breastfeeding and then early weaning - are normative practices. It has therefore been difficult to reach most pregnant women with the full package of PMTCT interventions (Rutenberg et al. 2003).

In Kenya, 270 new pediatric HIV infections occur each day and over 90 percent of infections in children are due to MTCT (NASCOP 2002). The severity of MTCT and resulting high incidence of HIV among children in Kenya is attributed to high rates of HIV infections in women, a large population of women of reproductive age, a high birth rate, and weak MTCT prevention interventions.

Kenya considers prevention of mother-to-child transmission of HIV one of the core strategies to reduce HIV transmission. However, it is possible that a PMTCT model that is purely medical and only situated in the ANC/MCH setting may be inadequate in Kenya for the following reasons:

- Low level of utilization of skilled birth attendants and various components of maternal and neonatal care.

- Fear of disclosure and stigma negatively influences women's participation in HIV counseling and testing, short course ARVs, and adoption of recommended infant feeding practices.

- Lack of resources and motivation for people to access PMTCT services.

\footnotetext{
${ }^{1}$ The term "full package of PMTCT services" as used in this report does not include PMTCT Plus activities such as ARV provision for the woman, partner, and children.
} 
Community-based approaches that complement medical services may not only increase awareness of services but also increase acceptance and uptake. To test this hypothesis, Horizons conducted research to examine whether implementing three community-based activities increased the utilization of PMTCT services and improved PMTCT-related knowledge and behaviors in Kibera, a highly populated urban slum in Nairobi. 


\section{Hgrizons}

\section{Methods}

\section{Study Objective}

The central objective of the study was to determine what effect three different community-based activities had on the utilization of key PMTCT services and indicators in Kibera, an informal settlement in Nairobi, Kenya.

\section{Description of the I ntervention}

Three interventions were designed and implemented in three separate study areas to increase access and utilization of PMTCT services: (1) using a mobile clinic to bring services closer to the people to improve physical access, (2) training TBAs to offer psychosocial support to pregnant women, and (3) training HIV-positive women as PMTCT promoters (peer counselors). To augment the three intervention activities, health information campaigns were conducted to support behavior change by increasing understanding and knowledge of factors surrounding HIV and AIDS and MTCT, and hence increase the demand for PMTCT. To ensure that good quality and standardized PMTCT services were offered at the clinics in the study area, health workers from both experimental and comparison arms were trained for 10 days using the national PMTCT curriculum developed and approved by National AIDS and STI Control Program (NASCOP). Trainees were drawn from the Ministry of Health facilities, Nairobi city council, private clinics, and the Network of AIDS Researchers in Eastern and Southern Africa.

\section{Study Partners}

The Horizons Program worked in collaboration with International Medical Corps (IMC) to design the study and its goals. IMC was responsible for implementing the three community-based activities/interventions and had prior experience working in the study area, namely providing medical care, health information, and emotional support to people living with HIV and their families. Steadman Research Services International (SRSI) was contracted to train interviewers, and collect and enter the data. Horizons participated in the training and also monitored the data collection.

\section{Study Sites}

The intervention activities took place in three separate areas of Kibera. The population of Kibera is estimated at 1.2 million people living in 25 square kilometers, making this the largest urban slum in sub-Saharan Africa (IMC/KICOSHEP 2003). The population is comprised mainly of young adults aged 18-35 years. There is a high level of deprivation in the slum. Residents have very poor access to social services such as clean water and sanitation coverage. As an informal settlement, housing is of extremely low quality and is overcrowded. Houses are pieced together with random bits of corrugated metal, cardboard, wood, and plastic (Hyman 2003). The majority live below the poverty line and can only afford one meal a day. Findings from a qualitative study conducted in Kibera by the African Population and Health Research Centre in 1999 suggested that there is poor access to maternal health services and a high prevalence of adverse pregnancy outcomes among its residents (APRHC 2002).

Kibera is sub-divided into 22 "villages." The intervention activities took place in eight of these villages: Lindi Siranga, Mugumoini, Mashimoni, Makina, Makongeni, Kichinjio, Kisumu Ndogo, and 
Gatwikera/Raila Estate. The total population of these villages is approximately 520,504 people. Women comprise 45 percent of the population.

The comparison area was Dagoretti, which has an estimated population of 240,509. Interviews took place in two health facilities where almost half (46 percent) of the population live below the poverty line with poor but slightly better infrastructure, sanitation, and maternal services than in Kibera.

\section{Study Design}

The quasi-experimental study consisted of a 4-cell design that measured how much of a difference increasing physical access or increasing psychosocial support (through two different methods) made in the use of various PMTCT services by pregnant and postpartum women in Kibera. Within this design, there were 4 different models:

Comparison: Dagoretti, a community near Kibera in which there were PMTCT services available in the traditional ANC/MCH clinical setting.

Exp 1: $\quad$ PMTCT services were brought to the community via a mobile clinic (villages: Lindi Siranga and Mugumoini).

Exp 2: $\quad$ TBAs were trained as PMTCT promoters (Mashimoni, Makina, Makongeni, and Kichinjio).

Exp 3: $\quad$ HIV-positive women who had already gone through the program were trained as PMTCT promoters and peer counselors (Kisumu Ndogo and Gatwikera/Raila Estate).

The research team determined the following outcomes that would be measured: ANC attendance, utilization of voluntary counseling and testing (VCT), delivery at health facility/with trained birth attendant vs. TBAs, Nevirapine uptake for mother and infant, receipt of infant feeding counseling and support, infant feeding practice, receipt of family planning counseling, intent for another pregnancy/child, intent to use contraception, and referral for care and support.

The sample size (450 women per area, which translated to a total sample size of 1,800 for the four arms of the study) was selected to detect a change of 10 percentage points in several key indicatorsi.e., percent of women who received HIV results, percent of women who delivered at health facility, and percent of women breastfeeding exclusively at six weeks.

\section{I mplementation of the Interventions}

\section{Traditional birth attendants (TBAs)}

TBAs were trained to encourage pregnant women irrespective of HIV serostatus to seek antenatal and delivery services at the health facilities and to offer psychosocial support to HIV-positive women. IMC trained 22 TBAs in September 2004 as PMTCT promoters, using a training curriculum developed by IMC through adaptation of the national PMTCT curriculum. The training took place over 14 half-days. The TBAs were trained on the following topics:

- Principles of adult learning and effective communication.

- Meaning of health and reproductive health.

- Sexually transmitted infections (STIs)/HIV/AIDS.

- Basic counseling skills. 


\section{Hgrizons}

- Record keeping and reporting.

- PMTCT.

- Family planning.

The following lists the scope of work given to the TBAs:

- Encourage women to access antenatal care early and attend regularly.

- Encourage women to go for HIV testing.

- Encourage women to get post-test counseling services.

- Provide post-test psychosocial support.

- Encourage all women to deliver at health facilities or at least by trained attendants.

- Conduct risk assessment and refer higher risk deliveries to health facilities.

- Encourage all HIV-positive women to take Nevirapine at the onset of labor and to go to the clinic within 72 hours if they delivered outside of clinic so their infants could receive the infant dose of Nevirapine.

- Instruct women on good breastfeeding practices.

- Encourage women to go to the clinic to get infant feeding counseling and support, and for growth monitoring and immunizations.

The research team developed a client card with pictures to aid illiterate TBAs in keeping records of the patient referrals and services they conducted. Information from the cards were compiled on a monthly basis and entered into an electronic database. Monthly meetings held with the TBAs provided opportunities to fine tune details, address problem areas and challenges, and hand in reports.

To increase the likelihood of attendance, TBAs received remuneration for attending monthly meetings. They also received financial compensation at the rate of $\mathrm{Ksh} 500^{1}$ per woman referred for hospital delivery, and Ksh 200 for every infant born to an HIV-positive mother referred within 72 hours after delivery for Nevirapine syrup and for each time they accompanied a woman for high-risk delivery. It was hoped that the compensation for the TBAs would off set their vested interest in carrying out home deliveries. On a weekly basis, IMC "animators" (community-based PMTCT promoters hired and trained by IMC) monitored their activities.

\section{Peer counselors}

Peer counselors were HIV-positive women who had already received PMTCT services. They were recruited to be mentors and educators to other women who were in the designated study villages and had tested HIV-positive. Twenty-two peer counselors were trained as PMTCT promoters using the same curriculum that was developed for the TBAs. Peer counselors were given the same scope of work as TBAs, with the exception of peer counselors not being expected to conduct risk assessments or refer higher risk deliveries to health facilities. Peer counselors participated in monthly meetings, which also served as support groups where they could both share their challenges as peer educators and meet with other HIV-positive women for mutual support. Peer counselors received remuneration of Ksh 1,000 per month for carrying out their scope of work and for attending the meetings.

\section{Mobile clinic}

IMC provided monthly mobile clinics that took PMTCT services directly to the population. This was carried out in Lindi, Siranga, and Mugumoini. IMC hired nurses on a daily basis to run the mobile

\footnotetext{
${ }^{1} 500$ Ksh (Kenya shilling) = approximately USD7.
} 
clinic from an IMC vehicle. Once the vehicle reached the target area, health providers set up a temporary clinic at an existing space, such as a church or meeting hall, and provided services. The team of health providers included a nurse midwife, counselor, and TBA. The role of the TBA was to identify, recruit, and encourage women to use the mobile clinic. IMC animators were part of the mobile team and assisted with dispensing drugs and weighing women and children. Service outputs were tracked using registers and data was transferred to an electronic database. The PMTCT services offered through the mobile clinic included:

- Routine ANC including STI screening and treatment.

- HIV counseling and testing.

- Nevirapine distribution for mother.

- Nevirapine distribution and administration for infant.

- Infant feeding counseling and support.

- Family planning counseling and services.

HIV-positive women were encouraged to breastfeed exclusively for six months then abruptly wean their children. All women were also encouraged to deliver at a health facility or at least by a trained attendant. HIV-positive women were advised to take their newborns delivered at home to the mobile clinic or to the health facility within 72 hours to get Nevirapine. Three mobile clinics (one per village) were conducted on a monthly basis from September 2004 to July 2005.

\section{Health information}

A five-day workshop was held in May 2004 to develop appropriate health information messages. The key behaviors that were promoted by the messages included safer sexual behavior, ANC attendance, delivery in health facility, male involvement, following PMTCT nutritional standards, and emphasizing family planning. Posters disseminating the messages were put up in health facilities in Kibera. Messages were also delivered through health talks with HIV-positive women in the support groups that were being supported by IMC.

\section{Training health facility staff}

IMC conducted three trainings lasting two weeks each for the health service providers from facilities in the project area. Ninety health service providers were trained using the national PMTCT curriculum developed and approved by NASCOP. The training was tailored to fill gaps in PMTCT services already being offered in areas including client-focused communication skills on infant feeding, VCT, family planning, and safe delivery practices. IMC's mandate was to ensure that the six main high volume clinics that were offering primary care had similar quality PMTCT services.

\section{Data Collection Procedures}

A cross sectional baseline survey of 1803 women with infants aged 10 weeks or younger was conducted from June 2004 to August 2004. This survey took place in five high volume primary health clinics in Kibera, namely Woodley health center, Lang'ata health center, Kibera health center, Wanga clinic, and AMREF clinic, as well as two high volume clinics in Dagoretti, namely Ngong Road and Riruta clinic. These health facilities were purposively selected because they served as a mechanism to try to obtain a representative sample of women from the study area who had recently given birth, since nearly all women took their infants for the first immunization visit (APHRC 2002). Interviewers took note of the villages that respondents came from; once the 450 sample size per arm was reached, the interviewers stopped interviewing from that arm but continued with eligible women from arms 


\section{Hgrizons}

that had not reached the target sample size. This process was repeated until the total sample size was achieved

The principal investigators from the Horizons Program developed the questionnaire, with input from IMC and SRSI. The questionnaire was translated into Kiswahili, and back translated. Questionnaires were pre-tested to confirm that respondents understood questions and that questions were phrased in ways that were culturally appropriate. Steadman recruited 10 female interviewers since it was more culturally appropriate to have women in the primary health clinics asking female respondents questions. These women were professional full time interviewers and had extensive previous experience in carrying out surveys. Staff from Horizons, IMC, and SRSI carried out training for five days, using participatory methods. Two interviewers were placed at each clinic, and they rotated after five days to reduce bias.

Interviewers approached every woman with an infant aged 10 weeks or less and asked if they would take part in the interview, and obtained informed consent from all respondents. Study participants were not given any monetary compensation. The interviews were carried out in Kiswahili and lasted approximately 45 minutes. Fourteen percent declined to participate.

The structured interviews covered the following topics: sociodemographic characteristics; knowledge of HIV transmission; exposure to previous community-based PMTCT support; patterns of formal health care and TBA use during pregnancy, delivery, and postpartum; women's experience with HIV counseling and testing in the antenatal care setting; short course ARVs; infant feeding; family planning; and referral for care and support.

After almost one year of implementation of intervention activities, a second cross-sectional follow-up survey was conducted in August 2005 and October 2005. The same criteria and process were applied as in the baseline survey and 1,813 women were interviewed.

Other data collection sources were used to complement the quantitative survey including documentation of IMC's introduction of community-based PMTCT services; documentation of cost inputs for the various intervention activities; in-depth interviews with a small convenience sample of mothers (48 HIV-positive and $10 \mathrm{HIV}$-negative); tracking of service data from clinics, mobile teams, TBAs, and HIV-positive peer counselors; and focus group discussions (FGDs) with TBAs and HIVpositive peer counselors (two FGDs each). This report utilizes data from the two surveys (baseline and follow up) and the qualitative data (in-depth interviews and FGDs).

\section{Ethical Procedures}

The research protocol was reviewed and approved by Kenya's National Council for Science and Technology and Ministry of Health and also underwent Population Council's ethical review process.The study advisory board also reviewed the research instrument and procedures, and provided guidance. Interviewers were trained on confidentiality, implemented the informed consent procedure for all women who were eligible, and only interviewed women who agreed to participate. Interviews were conducted in a private space and no identifying information was recorded in the questionnaire. Completed questionnaires were stored in locked cabinets, and access to the data was restricted to the research team. 


\section{Data Management and Analysis}

Steadman Research Services International was responsible for data entry. The company used a data entry technology where quantitative data is captured using a scanner (FORMIC program). To verify the data, 15 percent of questionnaires were rescanned and 10 percent were physically checked for consistencies.

Once the data entry was complete, the data set was sent to Horizons for data cleaning and analysis using the SPSS program. Unless otherwise indicated, Pearson's chi-square test of independence was used to determine significance. Results are considered statistically significant at or below the 0.05 level, and this is indicated by an asterisk $\left(^{*}\right)$.

\section{Limitations}

The study team acknowledges the limitation of a quasi-experimental design; the findings of this study may not be representative of all communities in Nairobi.

It is important to keep in mind when reviewing the data that the cross-sectional design does not allow for establishing a causal relationship between the program intervention and uptake of selected PMTCT services. 


\section{Hgrizons}

\section{Results}

\section{Profile of the Respondents}

Overall the women surveyed shared similarities across the comparison and intervention groups (see Table 1). The mean age of women at baseline and at follow up was about 25 years. Over 77 percent of women reported being married or cohabiting. Women from this study had an average of two children. The mean age of their infants was about five weeks. On average, two-thirds of women across the four groups at baseline and at follow up reported no income earning activity.

Table 1 Sociodemographic characteristics of sample, by study groups

\begin{tabular}{|c|c|c|c|c|c|c|c|c|}
\hline \multirow[t]{2}{*}{ Characteristic } & \multicolumn{2}{|c|}{ Comparison } & \multicolumn{2}{|c|}{ Mobile clinic } & \multicolumn{2}{|c|}{ TBAs } & \multicolumn{2}{|c|}{$\begin{array}{c}\text { Peer } \\
\text { counselors }\end{array}$} \\
\hline & $\begin{array}{c}\text { BL } \\
2004\end{array}$ & $\begin{array}{c}\text { FU } \\
2005\end{array}$ & $\begin{array}{c}\text { BL } \\
2004\end{array}$ & $\begin{array}{c}\text { FU } \\
2005\end{array}$ & $\begin{array}{c}\text { BL } \\
2004\end{array}$ & $\begin{array}{c}\text { FU } \\
2005\end{array}$ & $\begin{array}{c}\text { BL } \\
2004\end{array}$ & $\begin{array}{c}\text { FU } \\
2005\end{array}$ \\
\hline Number of women & 454 & 451 & 458 & 470 & 457 & 452 & 434 & 440 \\
\hline Mean age in years & 24.7 & 24.7 & 24.8 & 24.7 & 24.4 & 24.6 & 23.8 & 25 \\
\hline \multicolumn{9}{|l|}{ Marital status (\%) } \\
\hline Married/cohabiting & 81.2 & $87.6^{*}$ & 84.9 & $77.9 *$ & 82.5 & 79.4 & 83.5 & 80.9 \\
\hline Widowed & 1.1 & 0.7 & 1.7 & 2.6 & 1.1 & 1.3 & 1.6 & 3.2 \\
\hline Single/separated/divorced & 17.7 & 11.7 & 13.4 & 19.5 & 16.4 & 19.3 & 14.9 & 15.9 \\
\hline Mean \# of living children & 2.1 & 2.0 & 2.3 & 2.3 & 2.2 & 2.1 & 2.2 & 2.2 \\
\hline \multicolumn{9}{|l|}{ Education (\%) } \\
\hline None & 2.6 & 2.7 & 2.8 & 1.5 & 2.0 & 1.3 & 3.0 & 2.3 \\
\hline Incomplete primary & 22.9 & 18.6 & 35.2 & 31.7 & 30.9 & 26.5 & 36.4 & 30.9 \\
\hline Complete primary (8+) & 74.4 & 78.7 & 62.0 & 66.8 & 67.2 & 72.1 & 60.6 & 66.8 \\
\hline \multicolumn{9}{|l|}{ Occupation (\%) } \\
\hline None & 63.4 & 65 & 64.4 & $70.9 *$ & 60.8 & $67.7^{*}$ & 71.0 & $64.8^{*}$ \\
\hline
\end{tabular}

${ }^{*} \mathrm{p}<.05$ (statistically significant in 2-way comparison between baseline $(\mathrm{BL})$ and follow-up (FU) data)

There were no significant differences in age, marital status, mean age, number of living children, or occupation between the comparison and intervention groups between baseline and follow up. However, comparison group members had a slightly higher education (defined as those who completed primary education) than the intervention group.

At baseline, among the 24 HIV-positive women who participated in the in-depth interviews, 14 were married or cohabiting with a partner, one was single, three were separated from their partners, and six were widows. HIV-positive women had a median age of 26 years and a mean of three children. At follow up, 24 HIV-positive women participated, 18 were married/cohabiting, three were single and three were widowed. They had a median age of 25 years and a mean of two children. 


\section{Summary of Study Findings}

There were significant positive trends in most of the PMTCT study indicators during the period of the study (see Table 2). However, it is not possible to attribute all these positive trends to the communitybased interventions because similar positive trends were observed at the comparison site, with the exception of the infant feeding indicators, TBA utilization during last pregnancy, and Nevirapine uptake.

Table 2 Summary of main study outcomes by study groups

\begin{tabular}{|c|c|c|c|c|}
\hline Indicators & Comparison & $\begin{array}{l}\text { Mobile } \\
\text { clinic }\end{array}$ & TBA & $\begin{array}{c}\text { Peer } \\
\text { counselor }\end{array}$ \\
\hline \multicolumn{5}{|l|}{ MTCT knowledge: } \\
\hline MTCT occurs sometimes not always & + & + & + & + \\
\hline During pregnancy & + & 0 & 0 & 0 \\
\hline During delivery & + & + & + & + \\
\hline During breastfeeding & + & + & + & + \\
\hline \multicolumn{5}{|l|}{ ANC utilization: } \\
\hline Attended at least one ANC visit & + & + & + & + \\
\hline Also visited TBA & 0 & - & - & - \\
\hline \multicolumn{5}{|l|}{ Utilization of VCT: } \\
\hline HIV counseling & + & + & + & + \\
\hline Took an HIV test & + & + & + & + \\
\hline Received results & + & 0 & 0 & 0 \\
\hline \multicolumn{5}{|l|}{ Delivery at health facility with: } \\
\hline Trained attendant & + & 0 & 0 & + \\
\hline \multicolumn{5}{|l|}{ Nevirapine uptake for: } \\
\hline Mother & 0 & 0 & + & 0 \\
\hline Infant & 0 & 0 & 0 & 0 \\
\hline Receipt of infant feeding counseling & - & 0 & 0 & + \\
\hline \multicolumn{5}{|l|}{ Infant feeding practice } \\
\hline Exclusive breastfeeding & 0 & + & + & + \\
\hline Receipt of family planning counseling & 0 & - & 0 & 0 \\
\hline Intent of another pregnancy & 0 & 0 & 0 & 0 \\
\hline Intent to use contraception & 0 & - & - & - \\
\hline Referral for care and support & - & 0 & - & 0 \\
\hline
\end{tabular}

+ represents a significant positive change

0 represents no change

- represents a significant negative change

\section{Exposure to the intervention}

Results from the follow-up data collection showed that 213 out of 1,362 women interviewed from the experimental areas had either come into contact with or were exposed to at least one of the TBAs (64/452 = 14 percent), to an HIV-positive peer counselor $(79 / 440=18$ percent), or to the mobile clinic team $(70 / 470=15$ percent). Overall, there were no significant differences in mean age and number of living children, education and occupation between the exposed and non-exposed groups. 


\section{Hgrizons}

However, the exposed group had a slightly higher proportion of women who were married or cohabiting than the non-exposed group (see Table 3).

Table 3 Exposed versus non-exposed (follow-up results only)

\begin{tabular}{|c|c|c|c|}
\hline Indicators & $\begin{array}{l}\text { Exposed to at } \\
\text { least one } \\
\text { PMTCT } \\
\text { promoter } \\
(\mathrm{n}=213)\end{array}$ & $\begin{array}{c}\text { Not exposed } \\
\text { to any } \\
\text { PMTCT } \\
\text { promoter } \\
(\mathrm{n}=1,149)\end{array}$ & $p$ value \\
\hline \multicolumn{4}{|l|}{ Sociodemographics } \\
\hline Mean age of respondent & $25 \mathrm{yrs}$ & $25 \mathrm{yrs}$ & NS \\
\hline Mean number of living children & 2 & 2 & NS \\
\hline Education (5-8) (\%) & 66 & 64 & NS \\
\hline Married/cohabiting (\%) & 85 & 78 & 0.047 \\
\hline Unemployed (\%) & 63 & 69 & NS \\
\hline \multicolumn{4}{|l|}{ MTCT knowledge (\%) } \\
\hline MTCT occurs sometimes not always & 53 & 58 & NS \\
\hline During pregnancy & 57 & 49 & 0.030 \\
\hline During delivery & 87 & 78 & 0.004 \\
\hline During breastfeeding & 93 & 92 & NS \\
\hline \multicolumn{4}{|l|}{ ANC Utilization (\%) } \\
\hline At least attended one ANC visit & 100 & 98 & NS \\
\hline \multicolumn{4}{|l|}{ Utilization of VCT (\%) } \\
\hline HIV counseling & 94 & 95 & NS \\
\hline Took an HIV test & 91 & 94 & NS \\
\hline Received results & 95 & 94 & NS \\
\hline Delivery at health facility by trained attendant (\%) & 39 & 52 & 0.000 \\
\hline \multicolumn{4}{|l|}{ Nevirapine uptake (only HIV-positive) } \\
\hline Mother (\%) & 91 & 81 & NS \\
\hline Infant $(\%)$ & 95 & 93 & NS \\
\hline Receipt of infant feeding counseling (\%) & 61 & 55 & NS \\
\hline $\begin{array}{l}\text { Infant feeding practice } \\
\text { Exclusive breastfeeding (\%) }\end{array}$ & 65 & 72 & NS \\
\hline Receipt of family planning counseling (\%) & 40 & 34 & NS \\
\hline Intent of another pregnancy (\%) & 54 & 63 & 0.018 \\
\hline Intent to use contraception in the future (\%) & 84 & 78 & 0.036 \\
\hline
\end{tabular}

Women who had been exposed to at least one of the study interventions were significantly more likely to have more knowledge regarding modes of transmission of HIV from mother-to-child, to intend to use contraception in the future, to not want another pregnancy, and to have delivered their last child at home than the non-exposed group.

\section{Trends of Key Study Outcomes by Study Arms}

The earlier section of this report provided an overall picture of the study outcomes. This next section focuses on details of each key study outcome and its trend over time (from baseline to follow up). Additionally, significant changes are highlighted. 


\section{MTCT and knowledge of HIV}

Women were asked whether pregnant women who are HIV-positive could transmit HIV to their babies always, sometimes, or never. Overall, there were significant increases at follow up in the proportion of women with correct information from both the comparison and experimental areas (see Figure 1).

\section{Figure 1 Percentage of women who reported correctly that MTCT occurs "sometimes," by study groups}

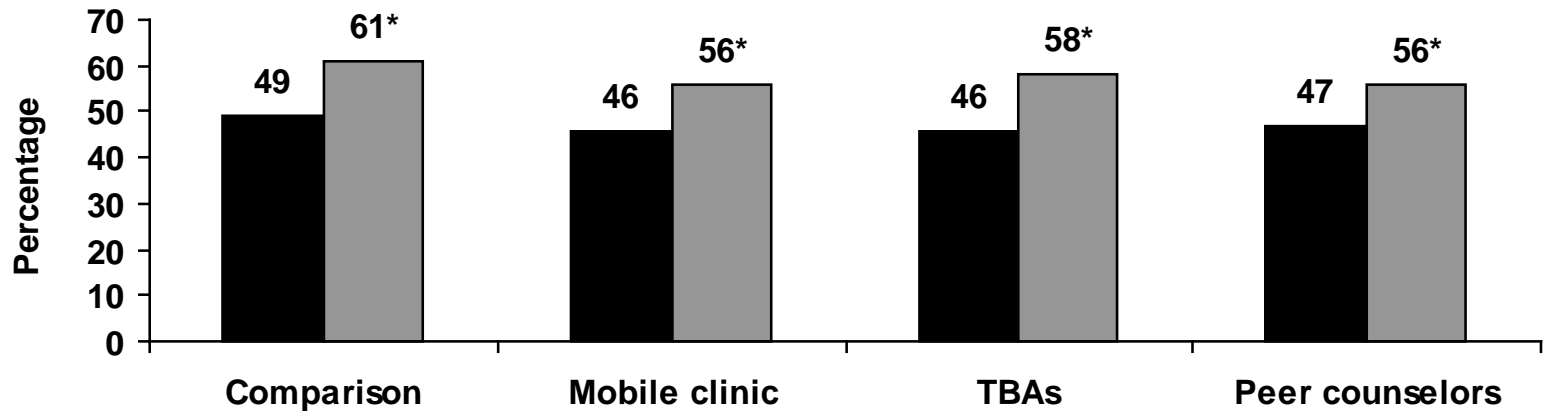

Baseline $(n=1,803) \quad \square$ Follow up $(n=1,813)$

${ }^{*} p<.05$

Women were also asked whether an HIV-positive woman could infect her baby during pregnancy, delivery, and breastfeeding. Responses indicated that the majority of respondents understood that MTCT could occur during delivery and breastfeeding (see Table 4). A notable proportion of the respondents did not know that an HIV-positive woman could infect her baby during pregnancy. At follow up, results show significant increases in the level of knowledge regarding MTCT through delivery and breastfeeding, in both the comparison and the three experimental areas. However, knowledge regarding HIV transmission during pregnancy remained low in all areas.

Table 4 Percentage of women who reported the correct timing of MTCT, by study groups

\begin{tabular}{lcc|cc|cc|cc}
\hline Characteristic & \multicolumn{2}{c|}{ Comparison } & \multicolumn{2}{c|}{ Mobile clinic } & \multicolumn{2}{c|}{ TBAs } & \multicolumn{2}{c}{ Peer counselors } \\
& BL & FU & BL & FU & BL & FU & BL & FU \\
& $\mathbf{2 0 0 4}$ & $\mathbf{2 0 0 5}$ & $\mathbf{2 0 0 4}$ & $\mathbf{2 0 0 5}$ & $\mathbf{2 0 0 4}$ & $\mathbf{2 0 0 5}$ & $\mathbf{2 0 0 4}$ & $\mathbf{2 0 0 5}$ \\
\hline An HIV positive mother can & & & & & & & & \\
infect her baby during... & & & & & & & & \\
$\quad$ Pregnancy (\%) & 45 & $53^{*}$ & 50 & 46 & 53 & 51 & 48 & 53 \\
Delivery (\%) & 71 & $84^{*}$ & 70 & $77^{\star}$ & 74 & $81^{\star}$ & 72 & $81^{\star}$ \\
Breastfeeding (\%) & 78 & $86^{*}$ & 87 & $92^{*}$ & 86 & $95^{\star}$ & 82 & $90^{\star}$ \\
\hline
\end{tabular}

${ }^{*} p<.05$ (between the two surveys)

Women were also asked whether they knew that drug treatment is available for people living with HIV. At follow up, there were significant increases in the percentage of respondents who knew that drug treatment was available for people living with HIV in both the comparison and experimental areas (see Figure 2). 


\section{Hgrizons}

Figure 2 Percentage of women who knew that drug treatment was available for people with HIVIAIDS by study groups

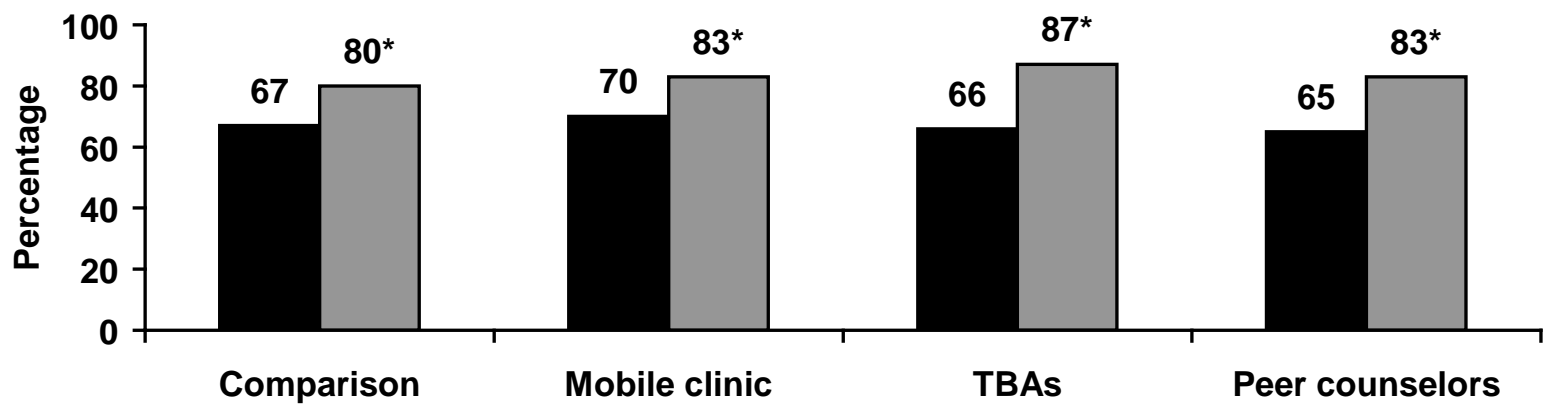

Baseline $(n=1,803) \quad \square$ Follow up $(n=1,813)$

${ }^{*} \mathrm{p}<.05$

Findings of significant increases in knowledge in the areas of MTCT and HIV in the community in both intervention and comparison areas suggest that changes may be due to external information, education, and communication sources not necessarily related to IMC's health information intervention activities.

\section{Self-reported HIV status}

Interviewers asked women whether they were willing to disclose their HIV status. Women who had ever been tested or received their HIV test results at ANC responded to this question. At baseline, of the 1,372 women who responded to this question, 4 percent $(n=60)$ reported that they were HIVpositive, 86 percent $(n=1,175)$ stated that they were HIV-negative and 10 percent $(n=137)$ did not indicate their status to the interviewer or said that they did not know their status (see Table 5). At follow up ( $\mathrm{n}=1,624)$, overall, data show that more women self reported as being HIV-positive ( 7 percent; $\mathrm{n}=114$ ) or HIV-negative (91 percent; $\mathrm{n}=1,479)$ as compared to baseline results. A significantly lower proportion (2 percent; $\mathrm{n}=31$ ) did not indicate their status at follow up. Anecdotal evidence from the health staff working in this community supports that in general stigma is decreasing and more people are willing to disclose their HIV-positive status than at the time when baseline data collection was being conducted.

Table 5 Percent distribution of women by self-reported HIV status at baseline and follow up

\begin{tabular}{lcc}
\hline Status & Baseline $(\mathbf{n}=\mathbf{1 , 3 7 2})$ & Follow up $(\mathbf{n}=\mathbf{1 , 6 2 4 )}$ \\
\hline HIV-positive & $\%$ & $\%$ \\
HIV-negative & 4 & 7 \\
Unknown HIV status & 86 & 91 \\
Totals & 10 & 2 \\
\hline
\end{tabular}

Still, HIV-positive status may have been underreported since service statistics from this community show that HIV prevalence among antenatal clinic attendees is about 14 percent. On the other hand, it 
is possible to find more HIV-negative than HIV-positive women at ANC clinics because they are more likely to be healthy and have healthy infants and to return with them for immunizations.

\section{ANC utilization}

ANC and TBA visits. Women were asked whether they had visited the clinic or hospital for a check up at least once during their last pregnancy. At baseline, most women had attended at least one ANC visit during their last pregnancy (see Table 6). These figures increased significantly at follow up among women from both the comparison and experimental areas.

Table 6 Percent of women who attended ANC and visited TBA during their last pregnancy, by intervention and comparison groups

\begin{tabular}{lcc|cc|cc|cc}
\hline Characteristic & \multicolumn{2}{c|}{ Comparison } & \multicolumn{2}{c|}{ Mobile clinic } & \multicolumn{2}{c|}{ TBAs } & \multicolumn{2}{c}{ Peer counselors } \\
& BL & FU & BL & FU & BL & FU & BL & FU \\
& $\mathbf{2 0 0 4}$ & $\mathbf{2 0 0 5}$ & $\mathbf{2 0 0 4}$ & $\mathbf{2 0 0 5}$ & $\mathbf{2 0 0 4}$ & $\mathbf{2 0 0 5}$ & $\mathbf{2 0 0 4}$ & $\mathbf{2 0 0 5}$ \\
\hline At least one ANC visit (\%) & 89 & $99^{\star}$ & 91 & $97^{\star}$ & 92 & $99^{\star}$ & 91 & $97^{\star}$ \\
Also visited TBA & 24 & 21 & 46 & $39^{\star}$ & 44 & $29^{\star}$ & 45 & $29^{\star}$ \\
\hline
\end{tabular}

${ }^{*} p<.05$ (between the two surveys)

Women were also asked whether they had also seen a TBA when pregnant. Overall, the proportion of women who reported visiting a TBA during their last pregnancy dropped significantly among women in the three experimental areas (see Table 6). The significant decline in the percent of women reporting visiting a TBA from the three experimental areas is likely to be associated with the intervention that was being implemented-TBAs and HIV-positive peer counselors were trained to encourage pregnant women to access antenatal care early and regularly at ANC, and pregnant women were discouraged from visiting TBAs. The same behavior was being promoted using posters at the health facilities and support groups from the study area. No significant changes were seen in the comparison area.

Baseline qualitative data from in-depth interviews showed that all the women who reported visiting a TBA ( $n=17$, i.e., 15 HIV-positive and two HIV-negative) did so for two specific reasons: for an abdomen massage to reposition the baby and for drinking traditional herbs perceived to ease stomach discomfort related to pregnancy.

When your pregnancy brings complications like feeling pain the TBA has traditional herbs that she gives you and the pain stops. When the baby is lying on one side in the womb she moves it to the center.

HIV-negative woman

The women also viewed the TBA as an emergency measure in case they were unable to reach the health facility for delivery, as expressed by one woman:

...At times when your due date has arrived and you cannot make it to the hospital, you choose to see a TBA who can help you deliver.

HIV-positive woman 


\section{Hgrizons}

Number of ANC visits. Information was gathered on the number of times study participants had received antenatal care at the clinic/hospital during their last pregnancy. Overall, at baseline, 41 percent of the women who had attended the ANC clinic during their last pregnancy $(n=1,633)$ had four or more visits (data not shown). This figure significantly increased to 54 percent at follow up (data not shown). These significant increases are seen in both the comparison and experimental areas, with the greatest increase occurring at the comparison site (see Figure 3).

\section{Figure 3 Percentage of women who reported a minimum of 4 ANC visits during last pregnancy by study groups}

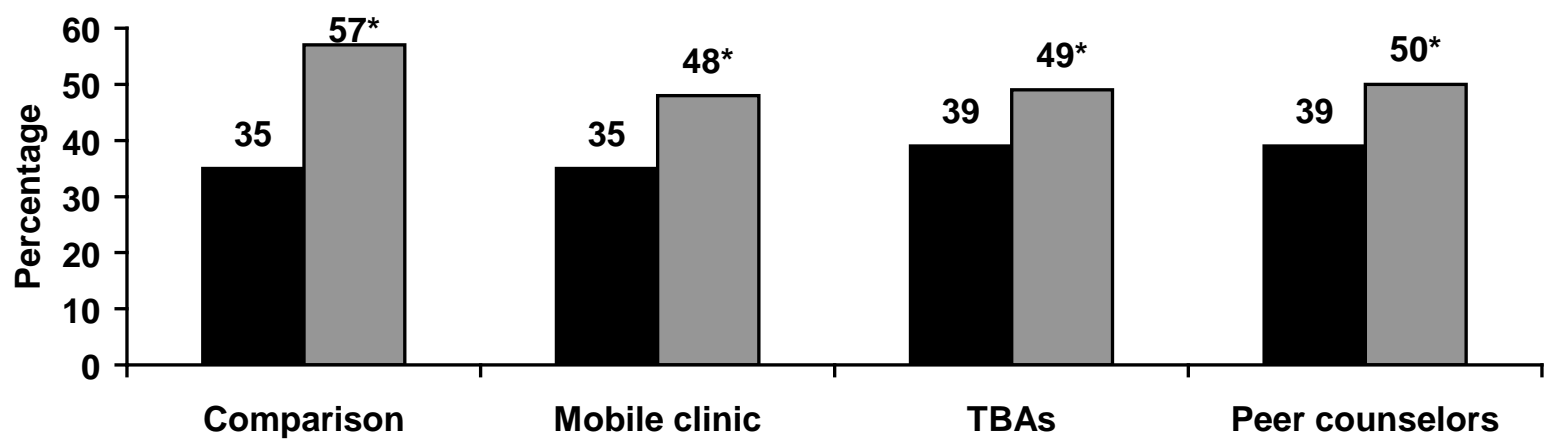

Daseline $(n=1,803) \quad \square$ Follow up $(n=1,813)$

${ }^{*} p<.05$

These findings suggest that the changes cannot be attributed to the intervention activities but rather to the general population trends, most likely due to the ongoing national campaigns for four focused ANC visits. The Ministry of Health in Kenya is implementing the WHO guidelines that recommend that a pregnant woman should attend a minimum of four comprehensive personalized antenatal visits spread out during the entire pregnancy, whereby specific focused activities are carried out as follows: first visit less than 16 weeks; second visit 20-24 weeks; third visit 28-32 weeks, and fourth visit 36 weeks (MOH and Population Council 2002).

\section{Utilization of counseling and testing services}

Women who had visited an ANC clinic during their last pregnancy (1,633 at baseline and 1,778 at follow up) were asked whether they had taken an HIV test. Overall, in 2004, 84 percent of the women who had visited an ANC clinic during last pregnancy took the test (see Figure 4). This figure increased significantly to 93 percent in 2005. A significantly higher proportion (88 percent) of the women who had attended at least one ANC visit at follow up $(n=1,778)$ reported receiving their HIV results compared to women at baseline $(n=1,633)$. A similar trend is seen among those who received HIV counseling (see Figure 4).

Results imply that over time women who come in for ANC services are more likely to accept HIV counseling and testing and receive their results. In addition, there seems to be increased coverage as the health system within this community is implementing routine and same day testing using rapid HIV tests kits to help avoid drop outs. 
Figure 4 Number in survey and proportion of women going through counseling and testing

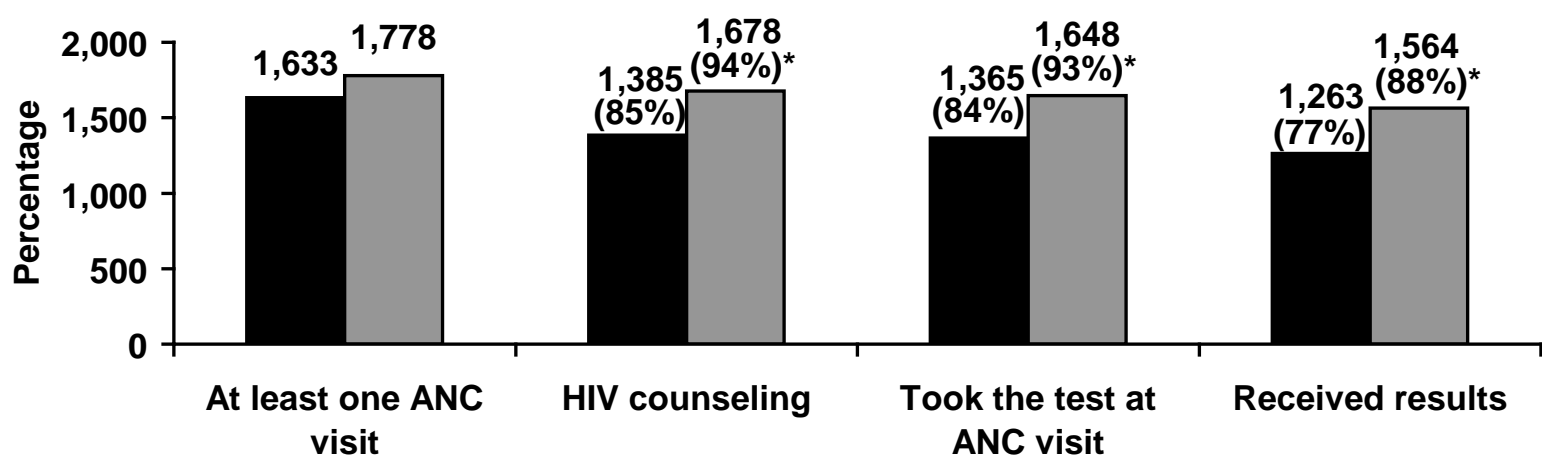

Baseline $(n=1,803) \quad \square$ Follow up $(n=1,813)$

${ }^{*} \mathrm{p}<.05$

There was a significant increase in the proportion of women who reported receiving HIV counseling and taking an HIV test at follow up in both the comparison and the three experimental groups (see Table 7). Women who had taken an HIV test at ANC were also asked whether they had received their HIV results. Nearly all (over 90 percent) these women reported receiving their results at baseline and these figures increased slightly one year later. Only women from the comparison group registered a significant increase compared to their counterparts from the three experimental areas. These results support the notion that undertaking HIV testing has become a standard practice among pregnant women in this community.

Table 7 Percent of women who attended ANC, took an HIV test, and received test results during their last pregnancy, by study groups

\begin{tabular}{lcc|cc|cc|cc}
\hline Characteristic & \multicolumn{2}{c|}{ Comparison } & \multicolumn{2}{c|}{ Mobile clinic } & \multicolumn{2}{c|}{ TBAs } & \multicolumn{2}{c}{ Peer counselors } \\
& BL & FU & BL & FU & BL & FU & BL & FU \\
& $\mathbf{2 0 0 4}$ & $\mathbf{2 0 0 5}$ & $\mathbf{2 0 0 4}$ & $\mathbf{2 0 0 5}$ & $\mathbf{2 0 0 4}$ & $\mathbf{2 0 0 5}$ & $\mathbf{2 0 0 4}$ & $\mathbf{2 0 0 5}$ \\
\hline HIV counseling (\%) & 84 & $94^{\star}$ & 83 & $93^{\star}$ & 85 & $96^{\star}$ & 88 & $95^{\star}$ \\
Took an HIV test (\%) & 83 & $91^{\star}$ & 80 & $94^{\star}$ & 81 & $92^{\star}$ & 86 & $94^{\star}$ \\
Received results (\%) & 91 & $97^{\star}$ & 93 & 92 & 93 & 95 & 93 & 96 \\
\hline
\end{tabular}

${ }^{*} \mathrm{p}<.05$ (between the two surveys)

\section{Delivery at health facility}

Women were asked where they had delivered their last child. At baseline 47 percent of women interviewed reported delivering their last child at a health facility (data not shown). This figure increased significantly to 54 percent one year later at follow up (data not shown). A higher proportion of women from the comparison (68 percent), TBA (52 percent), and peer counselor areas (50 percent) reported delivering their last child at a health facility at follow up compared to women from similar areas at baseline (see Figure 5). However, these changes were significant only among women from the comparison and HIV-positive counselor areas. The proportion of women reporting delivery at a health facility from the mobile clinic area remained constant between the two surveys. 


\section{Hgrizons}

Figure 5 Percentage of women who delivered last child at a health facility by study groups

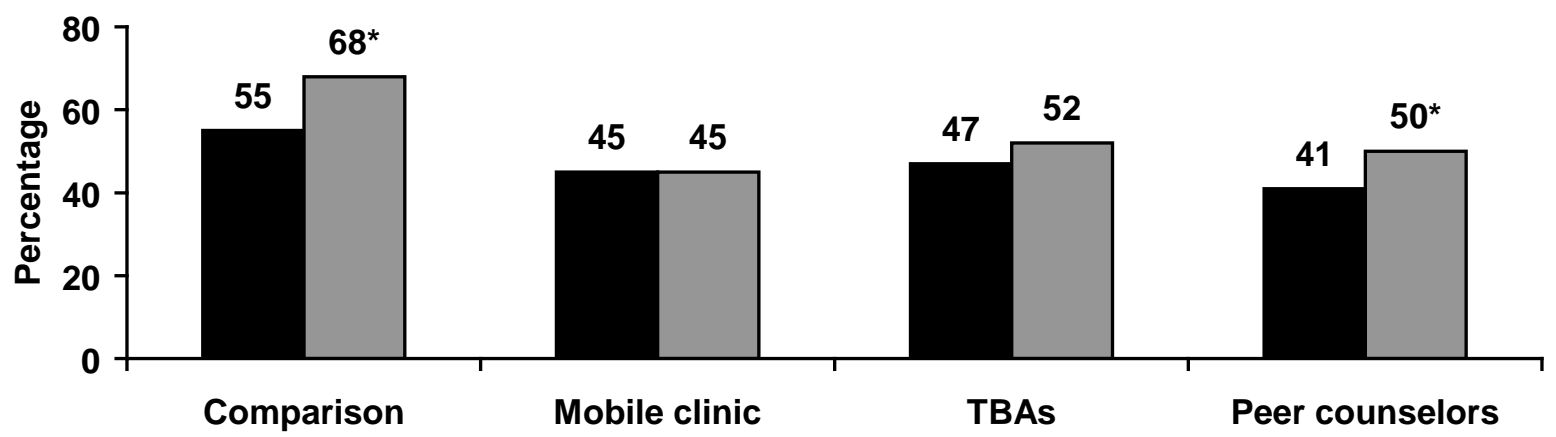

Baseline $(n=1,803) \quad \square$ Follow up $(n=1,813)$

${ }^{*} \mathrm{p}<.05$

The results from the TBA area were unexpected since the TBAs were being given an incentive to refer women within their designated villages to the health facility for deliveries. However, focus groups discussions held with TBAs at follow up revealed that a number of women were still opting for home deliveries (assisted by TBAs) due to poor reception by maternity nurses at health facilities, difficulties getting safe and affordable transportation to the facilities at the onset of labor especially at night, religious barriers, and myths.

The other challenge was being called at night that someone wanted to deliver. And you wonder how to get them to the hospital as there is no transport...so if we had a vehicle it would have been much easier getting them [pregnant women from study site] to hospital.

TBA

Some were saying that their traditions don't allow them to go to hospital, like Legio Maria [traditional religious sect].

Some say they fear going to the hospital for fear of having their babied swapped with HIVpositive ones.

Women were asked to discuss some of the factors that encouraged women in their community to utilize TBA services. Qualitative findings at baseline revealed that the majority of the HIV-positive respondents cited proximity, empathetic non-discriminatory delivery services, and the availability of credit facilities:

Because they [TBAs] are near and women can go to them any time and the TBAs can help them deliver on credit without paying cash but pay later.

HIV-positive woman

The services and care she gave me, like touching my body even though I am HIV-positive and she even agreed to help me. She did not leave or undermine me, love is what one requires and so I was not heart broken. She even gave me some advice and I felt like any other person.

HIV-positive woman 


\section{Nevirapine uptake}

Overall, at baseline, 45 out of the 60 (75 percent) self-reported HIV-positive women received Nevirapine. All 45 women who received it indicated taking the drug at the onset of labor. Forty-one out of the 45 (91 percent) women who got Nevirapine reported that their babies received the infant dose within 72 hours (data not shown). Among the 41 deliveries, 27 were at health facilities while 14 were home deliveries. These results may imply that even women with home deliveries could obtain an infant dose at the health facility if given information and support.

At follow up, out of the 114 women who indicated that they were HIV-positive, 96 (84 percent) reported having received and taken a drug to prevent mother-to-child transmission. Of the women who took the drug themselves, 94 percent indicated that their infants had also received Nevirapine syrup.

Although the numbers are small, there was a general increase in the proportion of women reporting receipt of Nevirapine and giving the infant dose in all the experimental areas at follow up compared to baseline (see Table 8). This increase was significant among women from the TBA area who reported receiving Nevirapine. On the other hand, at follow up fewer women from the comparison area reported receiving the drug and giving it to their infants than at baseline.

Table 8 Percent of HIV-positive women who reported receiving Nevirapine, taking the drug, and giving it to their infants within 72 hours after birth

\begin{tabular}{lrr|rr|rr|rr}
\hline Characteristic & \multicolumn{2}{c|}{ Comparison } & \multicolumn{2}{c|}{ Mobile } & \multicolumn{2}{c|}{ TBAs } & \multicolumn{2}{c}{ Peer } \\
& \multicolumn{1}{c|}{} & \multicolumn{2}{c|}{ clinic } & & & \multicolumn{2}{c}{ counselors } \\
& BL & FU & BL & FU & BL & FU & BL & FU \\
& $\mathbf{2 0 0 4}$ & $\mathbf{2 0 0 5}$ & $\mathbf{2 0 0 4}$ & $\mathbf{2 0 0 5}$ & $\mathbf{2 0 0 4}$ & $\mathbf{2 0 0 5}$ & $\mathbf{2 0 0 4}$ & $\mathbf{2 0 0 5}$ \\
\hline Number of women (n) & 13 & 19 & 21 & 32 & 8 & 27 & 18 & 36 \\
Received Nevirapine (\%) & 92 & 90 & 86 & 94 & 50 & $96^{*}$ & 61 & 64 \\
Received and took mother NVP (\%) & 100 & 100 & 100 & 100 & 100 & 100 & 100 & 100 \\
Received and gave infant NVP (\%) & 100 & 94 & 89 & 93 & 100 & 96 & 82 & 91 \\
\hline
\end{tabular}

$* p<.05$ (Chi square)

Researchers also asked respondents when they took the drug, providing options as follows: before labor began, at onset of labor, when baby was born, and another time. On average, 80 percent indicated taking Nevirapine at the onset of labor at baseline and follow up (data not shown).

\section{Infant feeding counseling and practice}

At baseline 58 percent of the women from the comparison area reported receiving infant feeding counseling; however, there was a significant drop to 39 percent at follow up (see Figure 6). The proportion of women from the mobile clinic remained unchanged (50 percent) between the two surveys. On the other hand, women from the TBA and peer counselor areas reported an increase in the proportion of women receiving infant feeding counseling at follow up compared to baseline (i.e., 51 percent vs. 58 percent, NS; and 50 percent vs. 60 percent, $\mathrm{p}<.05$, respectively). 


\section{Hgrizons}

Figure 6 Proportion of women who reported receiving infant feeding counseling from the health facility

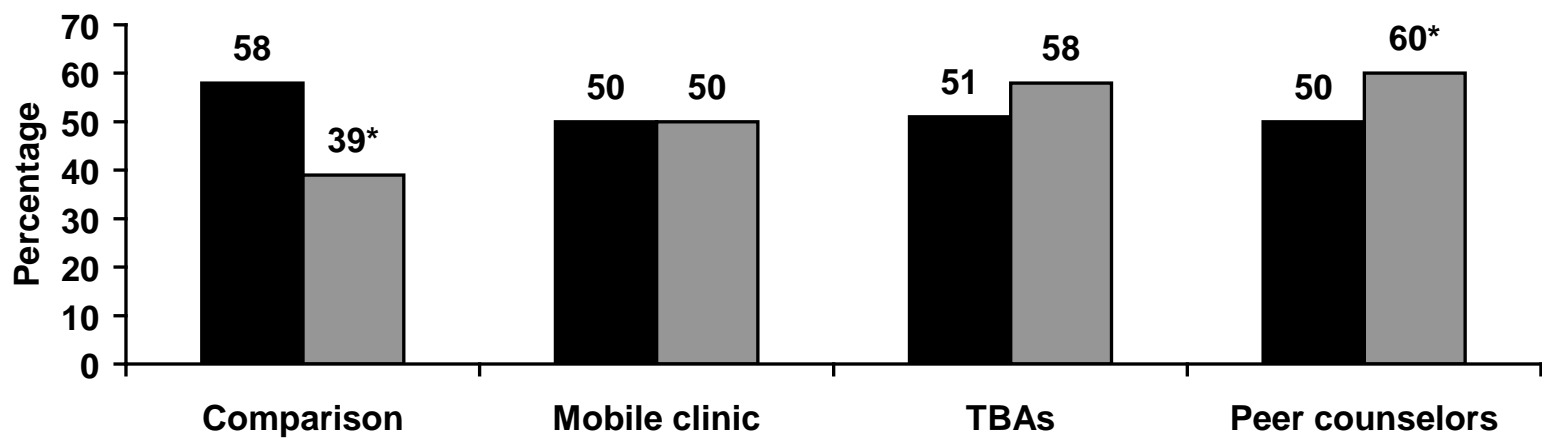

Baseline $(n=1,803) \quad \square$ Follow up $(n=1,813)$

${ }^{*} \mathrm{p}<.05$

Women were asked how they were feeding their babies. Nearly all women (95 percent) reported having breastfed in the last 24 hours. Results show that there was an increase in the proportion of women reporting exclusive breastfeeding at follow up compared to baseline (see Figure 7). The difference was significant among women from the intervention areas.

Figure 7 Proportion of women who reported exclusively breastfeeding last 24 hours

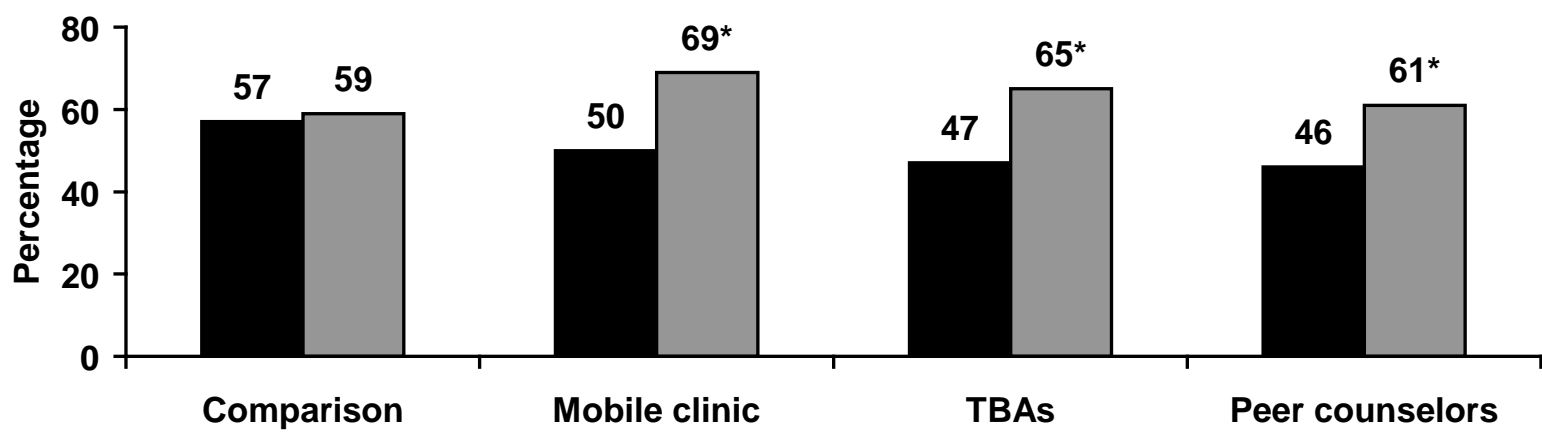

Baseline $(n=1,803) \quad \square$ Follow up $(n=1,813)$

${ }^{*} p<.05$

These increases were likely associated with the fact that researchers disseminated the baseline results to IMC, which organized several refresher infant feeding trainings for peer promoters aimed at improving the feeding practices in the community.

In-depth interviews revealed that the few women who opted to formula feed faced resistance from their immediate family and the community, as illustrated by the following quote:

Yes people have been asking me why I am not breastfeeding. So I told them that my breasts are sick and that the health provider has informed me that I can infect my baby...they have asked and are really curious. I told them I had lumps and the baby can also get them.

HIV-positive woman 


\section{Family planning counseling}

Women were asked whether a health provider had discussed family planning with them on the day of the interview or at an earlier clinic visit. Overall, 37 percent (data not shown) of study participants reported receiving family planning counseling at baseline. However, this proportion decreased to 35 percent at follow up (data not shown). Data by study area at follow up indicated that the proportion of women who received family planning counseling in the peer counselor area did not change, the proportion of women in the TBA area increased, and the proportion of women from the mobile clinic area significantly decreased (see Figure 8).

\section{Figure 8 Percentage of women who reported receiving family planning counseling by study groups}
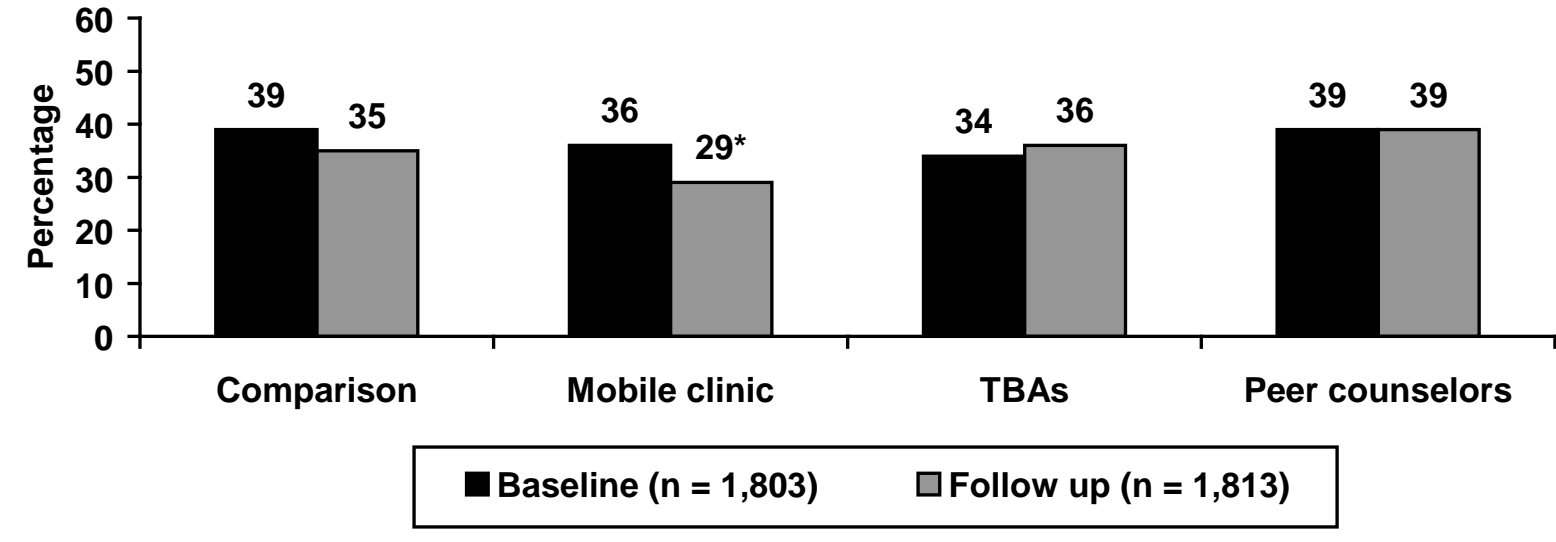

${ }^{*} p<.05$

In contrast to the quantitative sample, most HIV-positive women in the qualitative sample at baseline (21 out of 24) answered yes when asked if a health provider discussed family planning today or at an earlier visit. Twenty of the 21 women indicated receiving directive counseling. As reported by these women, the clear take home message was that family planning should be used. These women appeared to have been influenced by what the provider said regarding future childbearing; when explaining why they did not want more children, some women used language they reported receiving from providers. The main reason was to protect women's health given their serostatus:

She told me that since I was HIV-positive I should not continue to give birth because my health will continue to deteriorate.

HIV-positive woman

That it was not good to have another baby while I was HIV-positive because when I give birth I lose a lot of blood and may not live for long. Instead I was advised to use a condom.

HIV-positive woman

While more than half of the HIV-positive women who received counseling $(n=21)$ reported that providers recommended not having any more children in light of their serostatus, a few women remembered the provider also discussing birth spacing in the context of being HIV-positive:

She told me that if I continue giving birth my health would deteriorate considering my status. She also told me to plan my family so that I can give time for my children to grow accordingly.

HIV-positive woman 


\section{Hgrizons}

Several women recalled the provider discussing what to use for family planning, mentioning the importance of using condoms:

She told me it was better if I used a condom for family planning so as not to infect others or get more viruses.

HIV-positive woman

\section{Intent for another pregnancy}

Interviewers asked study participants whether they intended to have another child within 1 year, within 2-3 years, after 3 years, or not at all. Overall, more than half (63 percent at baseline and 61 percent at follow up) of the study participants reported that they intended to have another child in the future (data not shown). Figure 9 shows that there were no significant changes reported at follow up by study participants from all the study groups regarding their intentions to have another child.

Figure 9 Percentage of women who intend to have another child in the future by study groups

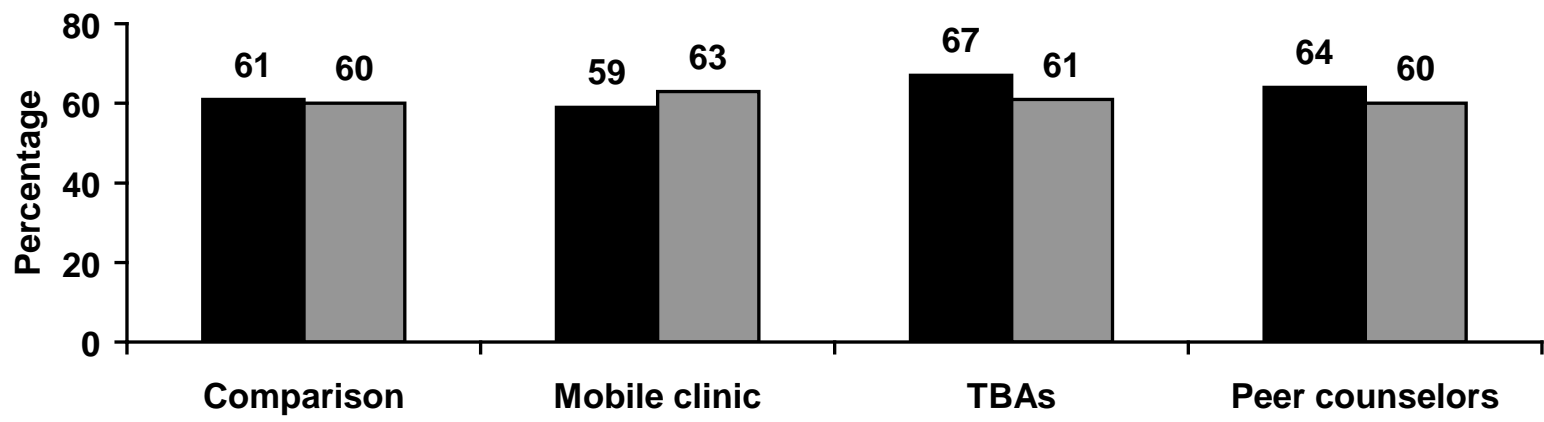

Baseline $(n=1,803) \quad \square$ Follow up $(n=1,813)$

According to the in-depth interviews, most HIV-positive women (15 out of 24) did not intend to have other children due to lack of resources, fear of getting an HIV-positive child, or feeling that having more children would be bad for their health:

...life has become hard [expensive] especially in terms of food and education.

HIV-positive woman

...by giving birth to more children, I would only be weakening my body and make myself grow weak or I can give birth to an HIV-positive child.

HIV-positive woman

However, some women reported that their husbands wanted more children as expressed by one woman:

It is not important for me to have more children, the reason is that my husband would like to have both male and female...that's why we want to try and see if we could have a boy.

HIV-positive woman

Others wanted more children in case a child died: 
...it's important for me to have 2 or 3 children, so that if God decides to take one I can remain with 1 or 2...there is a way whereby one can protect her baby from getting the virus.

HIV-positive woman

\section{Intent to use contraception}

Information was gathered on whether the study participants intended to use a family planning method in the future. Overall, at baseline 87 percent indicated that they intended to use a modern method of family planning in the future (see Figure 10). One year later, this figure had dropped significantly to 79 percent $(\mathrm{p}<.001)$ (data not shown). This decline was significant among women from the intervention areas (see Figure 10). No changes were observed in the comparison area.

Figure 10 Percentage of women who intend to use a modern family planning method in the future, by study groups

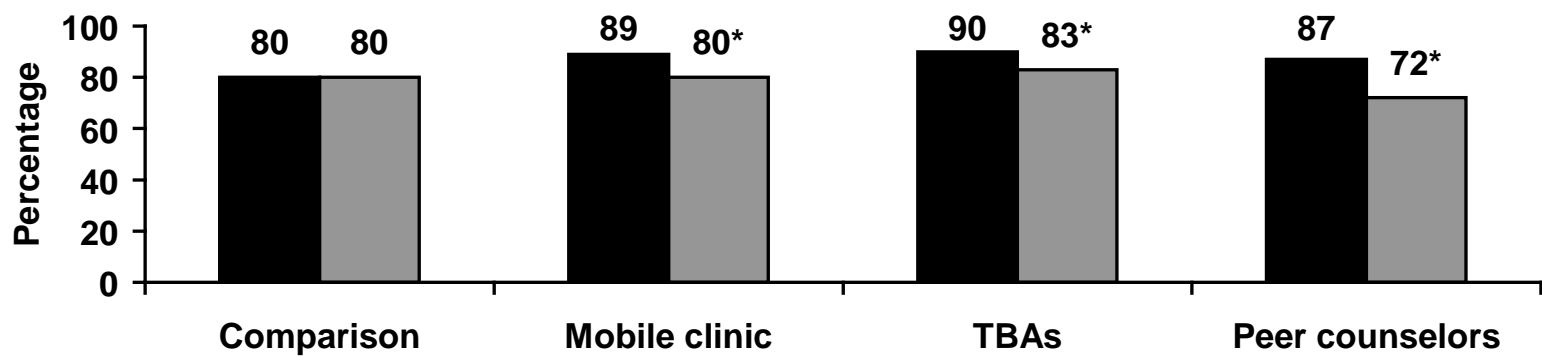

Baseline $(n=1,803) \quad \square$ Follow up $(n=1,813)$

${ }^{*} \mathrm{p}<.05$

Overall, most women planned to use a modern contraceptive method in the future. This demonstrates that in spite of the declining trends over time, there is still a broad demand for family planning.

\section{Care and support}

Women were asked, "Did you receive information about where you can go to receive more support about questions and concerns you may need about HIV?” Overall, at baseline 35 percent of the respondents reported that they had received information and support (data not shown). At follow up this figure dropped to 29 percent (data not shown). When results are disaggregated by experimental areas, respondents from the mobile clinic and TBA area reported the highest level of support compared to the comparison and peer counselor arm. However, these percentages dropped at follow up (see Table 9).

Table 9 Percentage of women who received information about where to get support on HIV concerns, by study groups

\begin{tabular}{lcc|cc|cc|cc}
\hline Characteristic & \multicolumn{2}{c|}{ Comparison } & \multicolumn{2}{c|}{ Mobile clinic } & \multicolumn{2}{c|}{ TBAs } & \multicolumn{2}{c}{ Peer counselors } \\
& BL & FU & BL & FU & BL & FU & BL & FU \\
& $\mathbf{2 0 0 4}$ & $\mathbf{2 0 0 5}$ & $\mathbf{2 0 0 4}$ & $\mathbf{2 0 0 5}$ & $\mathbf{2 0 0 4}$ & $\mathbf{2 0 0 5}$ & $\mathbf{2 0 0 4}$ & $\mathbf{2 0 0 5}$ \\
\hline Received information & 31 & $21^{*}$ & 38 & 33 & 38 & $30^{\star}$ & 34 & 32 \\
about HIV concerns (\%) & & & & & & & & \\
\hline
\end{tabular}

${ }^{*} \mathrm{p}<.05$ (between the two surveys) 


\section{${ }^{H}{ }^{\text {rizons }}$}

Women were then asked from whom they received this information, with multiple answers possible. Results from the follow-up data showed a significant increase in the proportion of women reporting receiving care and support from a health worker (41 percent at baseline to 95 percent at follow up; $\mathrm{p}<$ .05 ) in all the study arms (see Figure 11).

\section{Figure 11 Percentage of women who received information about HIV care and support from a health worker (only among those who received HIV information), by study groups}

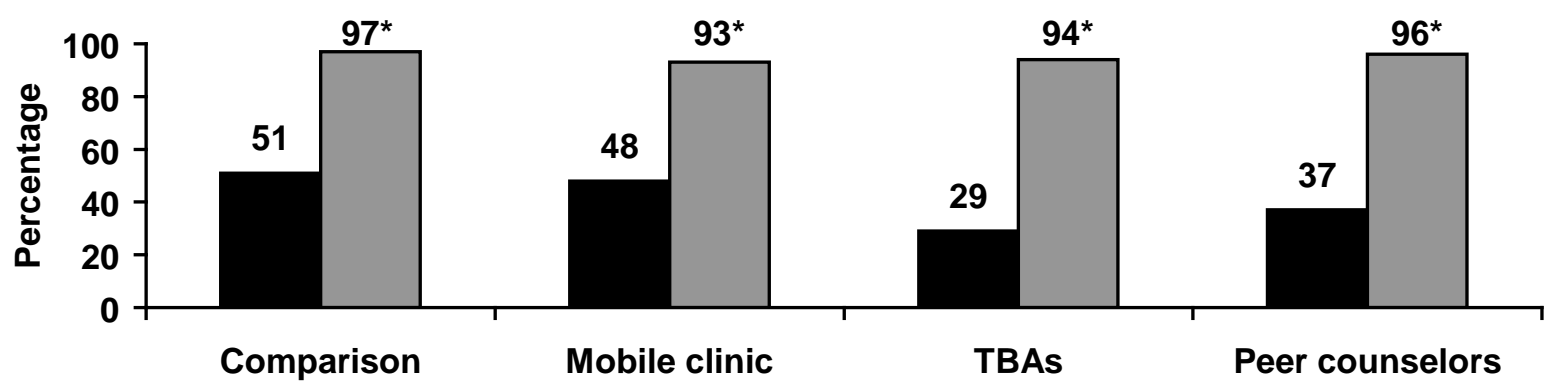

Baseline $(n=630) \quad \square$ Follow up $(n=528)$

$* \mathrm{p}<.05$

The in-depth interviews further revealed that the bulk of the HIV-positive women received care and support from the AMREF clinic:

AMREF...I get medicine and counseling and the baby gets milk [infant formula], also gets porridge supplement.

HIV-positive woman

Finally, results from qualitative data revealed that study respondents appreciated the psychosocial support they received from the PMTCT promoters (TBAs and HIV-positive peer counselors) as expressed by these two women:

...Sometimes I feel like that I have HIV but after receiving emotional support from her [HIV-positive peer counselor] I ignored the feelings and I saw that my body was fine. ... she said that anybody can live a normal life and work like anybody who does not have the virus so I was encouraged...I also interacted with other women who were infected just like me so I took heart.

HIV-positive woman

She $[T B A]$ is the one that encouraged me and gave me the first counseling and escorted me to the hospital.

HIV-positive woman

\section{Challenges to the I mplementation of the Community-based I ntervention}

The results of the study prompt the question: why didn't the community-based activities reach more women and have a larger impact? There are several possible explanations that could be useful to organizations implementing community-based PMTCT activities in a similar context. 
A major challenge was that the PMTCT promoters spent a lot of their time on income-generating activities to support their families rather than on project activities. Discussions from FGDs conducted with the TBAs revealed that most of them spent on average less than three hours, three times a week on implementation. Peer counselors spent two days a month on door-to-door campaigns and participated in IMC-sponsored support groups held on a weekly basis.

The rest of their time was dedicated to income-generating activities, since most of the women were widowed and unemployed. Those with spouses reported that their husbands were poorly paid or unemployed. Both the TBAs and the HIV-positive peer counselors also felt that the money they received as PMTCT promoters was not enough to allow them to fully dedicate their time (or any more time than they did) to the intervention.

Despite the low income, the PMTCT promoters said that they enjoyed working with women in their community:

...the money was little...my income is a big challenge and even having food to eat is difficult. I liked my work [PMTCT promoter]...being popular in a good way in the village and everyone greets me when I pass where I live and taking the mothers and babies to the hospital.

What made me like the work [PMTCT promoter] is that you assure the mothers that even if they get pregnant and they are HIV-positive the child has a chance to live and even herself. HIV-positive peer counselor

Another possible explanation that emerged from the FGD conducted with the peer counselors was the discovery that they did not typically disclose their HIV status to the pregnant women they interacted with due to their discomfort of being openly HIV-positive. Hence, while there were HIV-positive women who were engaging in community activities, the fact that they were not disclosing their status could make it difficult for study participants to know whether or not they had actually interacted with an "HIV-positive female counselor" as asked in the questionnaire or to get the benefits of hearing the experiences of openly HIV-positive women.

FGDs also revealed that although the TBAs and the HIV-positive peer counselors referred women to deliver at a stipulated health facility, a notable proportion of the study participants still preferred to deliver at home with TBAs due to several reasons, including lack of money for transport/ambulance and service fees at health facilities, insecurity in the informal settlement especially at night, religious beliefs, and myths.

Finally, although the intervention was initially planned to be implemented for 12 months, due to slight delays in the starting of the research activities coupled with a shortened funding timeline for the intervention, the intervention activities were implemented for roughly seven months. This meant that there was not enough time for the intervention to be firmly established in the intervention areas, and for it to penetrate deep into the study area. This contributed to only a small percentage of respondents reporting having interacted with the PMTCT promoters. 


\section{Hgrizons}

\section{Conclusions}

The Kibera community-based project aimed to determine what effect three different community-based activities had on the utilization of key PMTCT services and indicators. Data from this study showed that there were positive trends during the study period in most of the PMTCT indicators. These trends showed that the majority of respondents understood that MTCT could occur during delivery and breastfeeding, but a notable proportion did not know that an HIV-positive woman could infect her baby during pregnancy. Quantitative data also showed high levels of HIV testing, and qualitative discussions revealed that women from this community reported that getting tested at ANC was a standard practice. Results also found that over time there was a reduction in the number of women opting out of PMTCT services due to the fact that the health system within this community was adequately implementing same day testing using rapid HIV tests kits. Nevirapine uptake of mother and infant and delivery at the health facility with a skilled attendant significantly increased at follow up, while utilization of TBAs dropped. The study also found that there was a significant increase in the proportion of women from the experimental areas exclusively breastfeeding their infants at follow up.

However, it is not possible to attribute all these positive trends to the community-based interventions because similar positive trends were observed at the comparison site, except for the infant feeding indicators, TBA utilization during last pregnancy, and Nevirapine uptake. The inability to measure an effect may be due to the small proportion of the study respondents (16 percent) who reported interaction with the interventions, namely the mobile clinic providers, traditional birth attendants, and HIV-positive peer counselors.

The study also revealed some gaps that need programmers' attention-i.e., family planning counseling and utilization of modern contraceptive methods was low in this community. In addition, half of the respondents had intentions of another pregnancy in the future, while most reported that they intended to use contraceptives in the future. These results reveal that there is a large unmet need for family planning services in this community to help women achieve their sexual and reproductive health goals.

In this study population, PMTCT programs are reaching urban poor women with key PMTCT services within the traditional ANC/MCH setting. Community-based promoters have the potential to complement facility-based PMTCT services, but they need to increase their coverage and their activities need to be rigorously implemented in order to fully test their effectiveness.

Recommendations for other organizations exploring community-based PMTCT activities in a similar context are as follows:

\section{Community provider}

- For a community model to be successful in a resource-constrained setting such as an informal settlement with poor transport, access to health facilities is key. This means the provision of community ambulances, well-equipped maternities, and good roads/infrastructure.

- HIV-positive female counselors can provide psychosocial support to enable HIV-positive women to adhere to recommended PMTCT infant feeding practices which sometimes go against social norms

- In a resource constrained setting, adequate financial resources are important. A lesson learned from this study is that although the PMTCT promoters were enthusiastic about implementing the intervention, their time was divided between their new role and doing income-generating activities to meet their family financial needs since most of them were breadwinners. The little 
stipend they received for their time was not adequate to cover for their daily needs, which resulted in sub-optimal implementation of the community-based model.

- Peer counselors should be counseled and trained on how to deal with stigma and discrimination so that it does not become a barrier to undertaking their assignment as PMTCT promoters, and should be made aware of the importance of disclosure as part of their roles as peer educators.

- Community-based intervention programs need adequate time in order for them to take root and maximize their reach in the community.

\section{Health facility}

- Health providers require routine refresher PMTCT training and support supervision to ensure that they offer good quality service. Additionally, they should be trained on how to handle clients (e.g., good reception techniques) so that they do not become a barrier to utilization of services.

- There is a need for more staffing and support supervision to ensure that important PMTCT services such as family planning and infant feeding services are adequately offered to all PMTCT clients. 


\section{Hgrizons}

\section{References}

African Population and Health Research Centre (APHRC). 2002. Population and Health Dynamics in Nairobi's informal settlement. Nairobi: African Population and Health Research Centre.

Central Board of Statistics et al. 2003. "Kenya demographic and health survey 2003: Preliminary report.” Calverton, MD: MEASURE DHS+.

Guay, L.A. et al. 1999. "Intrapartum and neonatal single-dose nevirapine compared with zidovudine for prevention of mother-to-child transmission of HIV-1 in Kampala, Uganda: HIVNET 012 randomized trial,” Lancet 354: 795-802.

Hyman, J. 2003. “Supporting Nairobi’s most vulnerable residents,” Global AIDSLink 83: 12-14.

IMC/KICOSHEP. 2003. Mobile Clinic Reports from 'Kibera Mobile Outreach Project': May 2002May 2003.

National AIDS and STD Control Programme (NASCOP). 2002. National Guidelines: Prevention of Mother-to-Child HIV/AIDS Transmission (PMTCT). Nairobi: NASCOP.

Rutenberg, N. et al. 2003. Evaluation of United Nations-supported pilot projects for the prevention of mother-to-child transmission of HIV. New York: UNICEF.

Shaffer N. et al. 1999. "Randomized placebo-comparison led trial of short-course antenatal zidovudine to reduce perinatal HIV transmission, Bangkok, Thailand,” Lancet 353: 781-85.

UNAIDS. 2006. Report on the Global AIDS epidemic: A UNAIDS $10^{\text {th }}$ anniversary special edition. Geneva: UNAIDS.

United Nations Children's Fund (UNICEF). 2007. Children and AIDS: A stocktaking report. New York: UNICEF. 


\section{Hgrizons}

Horizons is a global operations research program designed to:

- Identify and test potential strategies to improve HIV/AIDS prevention, care, and support programs and service delivery.

- Disseminate best practices and utilize findings with a view toward scaling up successful interventions.

\section{(2) Population Council}

Horizons is implemented by the Population Council in collaboration with

- International Center for Research on Women (ICRW)

- International HIV/AIDS Alliance

- PATH

- Tulane University

- Family Health International (FHI)

- Johns Hopkins University

For more information, please contact:

Horizons Program, Communications Unit 4301 Connecticut Ave, NW Suite 280

Washington, DC 20008 USA

Tel: 202-237-9400

Fax: 202-237-8410

Email: horizons@popcouncil.org www.popcouncil.org/horizons 